\title{
Potentials of Gamification in Learning Management Systems: A Qualitative Evaluation
}

\author{
Jan Broer ${ }^{(\bowtie)}$ and Andreas Breiter \\ Institute for Information Management Bremen, \\ University of Bremen, \\ Bremen, Germany \\ \{jbroer,abreiter\}@ifib.de
}

\begin{abstract}
Besides game-based learning, gamification is an upcoming trend in education, studied in various empirical studies and found in many major learning management systems. Employing a newly developed qualitative instrument for assessing gamification in a system, we studied five popular LMS for their specific implementations. The instrument enabled experts to extract affordances for gamification in the five categories experiential, mechanics, rewards, goals, and social. Results show large similarities in all of the systems studied and few varieties in approaches to gamification.
\end{abstract}

Keywords: Gamification $\cdot$ LMS $\cdot$ Learning $\cdot$ Management

\section{Introduction}

Experiments of classroom gamification are becoming increasingly common (e.g. [1]). Gamification is likewise found in information systems, especially those supporting online communities (e.g. [2]). It is therefore not surprising that learning management systems (LMS) have been adopting gamification in some form or another. In a ranked list of the top 20 most popular LMS by Capterra [3], 10 systems are listed as including gamification. Unlike game-based learning (cf. [4]), gamification does not employ full-fledged games but game design elements in non-game contexts [5]. In most cases, this is done to improve user engagement [6], to motivate users [7], or to support value creation [8]. In education, goals of gamification are similar. Non-game systems, such as LMS, are enhanced with aspects of games in order to engage students with the content of the course. Outcomes reported in studies include higher performance on tasks, higher attention to reference materials, higher activity in a system, and self-reported satisfaction with the course or learning value. See [9] for a good overview. As in other contexts, reports on gamification in education and are generally positive, but empirical validation is limited to a small subset of possible contexts. In [10] we have shown the same phenomenon for gamification in general and discussed possible implications thereof. 


\section{Methods}

Following Arjoranta's [11] suggestion of focusing definitions on Wittgensteinian family resemblances instead of a common core, we performed a survey among experts on gamification in order identify key terms that are relevant for describing gamification and, by corollary, indicators of the presence of gamification. A catalogue of questions was derived from the survey results and applied to five popular LMS. The instrument consists of 38 items, each with a standardized part categorizing the response into yes, no, or maybe and an open part detailing the reasoning for the answer. "Maybe" responses were reserved for cases in which a system had potential for gamification, but relied on user input for it. The items are divided into five categories - experiential, mechanics, rewards, goals, and social (see Table 1 for example items). Four evaluators applied the instrument to each of the five LMS - one expert and three evaluators with basic training in gamification. Agreement on the standardized part of each item was calculated to validate the instrument. Following Capterra's October 2014 [3] ranking, we analyzed the following five LMS focused on K-12 or higher education in this research (in order of ranking): Moodle, Edmodo, Blackboard Learn, Schoology, and Canvas.

Table 1. Example items from the instrument for evaluating gamification. Full instrument available at: https://db.tt/DaZNzaTA

\begin{tabular}{|c|c|c|c|}
\hline \# & Category & Subcategory & Question(s) \\
\hline E3 & Experiential & Challenge & $\begin{array}{l}\text { Does the system include tasks designed to be } \\
\text { challenging for the user to complete? }\end{array}$ \\
\hline M1 & Mechanics & Collecting & $\begin{array}{l}\text { Does the system provide opportunities for the user to } \\
\text { collect things? }\end{array}$ \\
\hline M7 & Mechanics & Storytelling & Does the system make use of storytelling? \\
\hline R5 & Rewards & Points & $\begin{array}{l}\text { Does the system reward users with points of any } \\
\text { kind? }\end{array}$ \\
\hline G1 & Goals & Clear goals & $\begin{array}{l}\text { Does the system provide the user with clear } \\
\text { goals/ideas about what to do next? }\end{array}$ \\
\hline S1 & Social & $\begin{array}{l}\text { Fame/getting } \\
\text { attention }\end{array}$ & $\begin{array}{l}\text { Does the system provide means for the user to gain } \\
\text { fame/attention? }\end{array}$ \\
\hline
\end{tabular}

\section{Results}

Experiential. The experiential items show a very high overlap of gamification in the five analyzed LMS. Accomplishment, autonomy, learning/mastery and positive emotions were found in all five systems. All systems had the potential to provide the user with a form of accomplishment through the successful completion of tasks and courses and through the awarding of badges and grades. These factors are also the causes of positive emotions - none of the systems was found to include additional elements specifically designed to afford positive emotions. Mechanics often found in games that 
give players a feeling of accomplishment even when they are not successful, are not obvious in the systems analyzed here. Challenge and competence were extreme examples of this, as they were uniformly coded as being potentially available but depending on instructor input.

Autonomy was reflected in the student's ability to choose when and where to complete their tasks. Depending on instructor input, they may still be bound to a strict syllabus, however. Learning/mastery was usually present in one of two ways: Users were allowed to re-take quizzes and assignments or there was a dedicated mastery system. Such systems were usually based on formative assessment and the alignment of tasks to goals. Affordances for curiosity, purpose, and concentration were not found in either platform (Fig. 1).

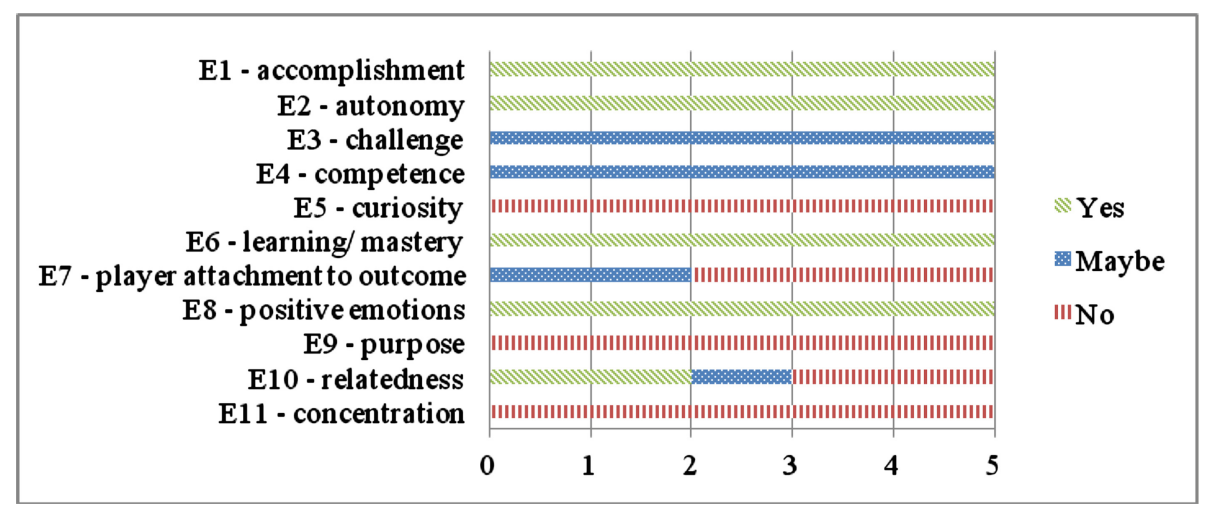

Fig. 1. Results in the "experiential" category, showing the number of LMS coded as expressing each subcategory (Yes), potentially expressing it (Maybe) and not expressing it (No). Results for all categories can be found at: https://db.tt/o4mRaeev

Mechanics. The major gamification mechanics found in the different LMS in the expert review were collecting, documentation of behavior, and player effort. Collecting can mostly be seen as an incidental result of the ubiquitous use of badges in these LMS. Documentation of behavior was generally available in different forms. Some systems provided activity streams for the users themselves, teachers, or parents.

Player effort was a difficult item to apply as the system needs to provide a measure of success that is distinct from outside measures of the same if it is to be coded in this way. This is directly related to the item of "variable outcome". All systems provided variable outcomes in so far as users could get different grades and potentially fail to complete the course. These are hardly different from the same mechanic in traditional courses, however, and therefore hard to ascribe to gamification.

Fixed rules were also rare beyond the norm provided by the frameworks of a school course and an information system. Blackboard Learn provided the ability to define rules for obtaining badges, which can be seen as similar to games. In all other systems, badges were handed out by the instructor, allowing for arbitrariness. Schoology and 
Blackboard Learn were the only systems found to offer time pressure. Here, instructors can set time limits for specific questions/tasks. A common element in many games, time pressure seems to be rare in LMS. Nurturing/growing and storytelling are completely absent from the analyzed systems, even though both were thought to be highly relevant for gamification by the experts in the preceding survey.

Rewards. The rewards section is essentially identical for all five surveyed systems. All of them offer intangible rewards in the form of badges and some measure of progress. None made use of points or levels, which are equally commonly found in gamification literature. It should be noted that LMS with such features exist; they were simply not part of the sample analyzed here. Progress was shown through a mastery system in some cases, through general course completion in others. Some LMS allowed the sharing of badges outside the application through Mozilla's Open Badges program.

Goals. Goals were almost identically rated among all systems as well. In each case, instructors had the ability to subdivide coursework in such a way that the goals for the users are clear and potentially achievable. All systems show users in an understandable way, which next steps they should take, provided that the teacher has set up such steps. Some systems, such as Blackboard Learn, specifically encourage teachers to set up tasks that align with course goals, facilitating clear and achievable goals.

Social. The social category shows actual conceptual differences between the systems. Tools for collaboration were explicitly built into some systems (Blackboard Learn and Canvas), and possible in others through communication tools. Some systems, such as Edmodo, explicitly excluded communication between students from their features, while others even provided chat rooms and discussion boards (e.g. Blackboard Learn). Only Moodle allows for competition in the form of a leaderboard (through a third party plug-in), underlining an interesting result from the expert survey: Experts considered competition very important for a description of gamification in general, but most did not consider it important for their own chosen implementation of gamification. Finally, most systems did not make use of social incentives in general or social engagement loops in particular. Exceptions are Blackboard Learn and Canvas that provide notifications to users, when other users show activity.

\section{Discussion}

Probably the most interesting result of this study is the similarity of the implementation of gamification in different LMS. Only for 6 of 38 items was there a divergence of results that included more than one system. It is safe to assume that observation of the competition leads to a converging feature space. One could further postulate that experimental changes are more dangerous to a company with a large established user base than they would be to a new competitor. It would therefore be unwise to assume that this examination of the top five most popular LMS can give a complete overview over the variations of gamification used in LMS.

What, then, can we learn from such study? For one, it is very informative to study which known affordances for gamification are absent from our sample. Almost all 
authors on the topic agree that points, badges, levels, and leaderboards are the most commonly used of such affordances. Hamari et al. [12] as well as Dicheva et al. [9] have shown this in their reviews. While badges were found in all the LMS studied here, points, levels, and leaderboards were not. All of these are trivial to include on a technical level, making it likely that a conscious decision has led to their absence. The expert survey that this study was based on already revealed that most participants found competition to be important to describe gamification in general, but not to describe their own chosen gamified system. This implies that they made the conscious choice of not employing competition. Results from empirical studies on gamification, show that competition can be regarded negatively by a subset of users.

The lack of points and levels is harder to explain. One reason might be that students are already being given either points or grades for their assignments and that the addition of another set of points might be confusing. It is also difficult to reward leveling up in a LMS, as one cannot give material advantages to some students and not to others. Other affordances that are notably absent are those built on storytelling or nurturing/growing. Storytelling especially requires large content creation effort. Furthermore, both elements would likely require a lot of tailoring towards the content being delivered in the LMS. A LMS could only hope to implement tools that help instructors include storytelling or nurturing/growing into their courses, not provide complete packages.

\section{Conclusion}

Employing a catalog of 38 questions, we evaluated five popular learning management systems towards their use of gamification. Results show that all five systems are very similar in this aspect. All systems employ gamification but do so at a rather shallow level. Badges are ubiquitous, other affordances rare. In many cases, whether a learning management system affords gameful experiences is not so much dependent on the system, but the way it is set up by the instructor. Challenge and competence are two example items that completely depend on how the instructor sets up his or her course. For other items, support for gameful experiences could be identified, but was not necessarily linked to the use of game (design) mechanics. Autonomy, for example, was often afforded through the possibility to choose time and order of completing tasks and a sense of mastery through alignment of tasks to learning outcomes. Only very few affordances, mainly badges, can be directly tracked back to their use in games. Overall, gamification as offered in these learning management systems is still far behind even the approaches evaluated in research. There is a lot of room for additional gamification in learning management systems, but the effectiveness of those approaches has yet to be shown.

The reliance on instructor input for many items suggests a challenge for further implementations of gamification in educational settings. It will be interesting to see, how much gamification a learning management system can provide by default and how much can only be added through an instructor. One could further subdivide the discussion about possible affordances into two subsets - affordances for gameful experiences and affordances for creating affordances for gameful experiences. The former is 
likely to be cheaper due to its mass-market approach, while the latter is likely to be much more effective due to instructors tailoring gamification directly to their needs. This distinction brings forth the question of whether an evaluation of gamification at the system level even makes sense in systems that rely highly on user created content (i.e. LMS) or whether one has to evaluate the content within those systems instead. Goal alignment systems suggest the possibility for a combination of the two - learning goals would be adapted at the class level, for example, but gamified automated systems could make use of those goals to provide a more gameful experience.

\section{References}

1. Hanus, M.D., Fox, J.: Assessing the effects of gamification in the classroom: a longitudinal study on intrinsic motivation, social comparison, satisfaction, effort, and academic performance. Comput. Educ. 80, 152-161 (2015)

2. Hamari, J.: Transforming homo economicus into homo ludens: A field experiment on gamification in a utilitarian peer-to-peer trading service. Electron. Comm. Res. Appl. 12, 236-245 (2013)

3. Capterra: Top LMS software. http://www.capterra.com/learning-management-systemsoftware/\#infographic

4. Prensky, M.: Digital game-based learning. Comput. Entertainment 1, 21 (2003)

5. Deterding, S., Dixon, D., Khaled, R., Nacke, L.: From game design elements to gamefulness: defining "gamification". In: Proceedings of MindTrek 2011, pp. 9-15. ACM, New York, NY, USA (2011)

6. Zichermann, G., Cunningham, C.: Gamification by Design: Implementing Game Mechanics in Web and Mobile Apps. O'Reilly Media, Sebastopol (2011)

7. Blohm, D.I., Leimeister, P.D.J.M.: Gamification. Bus. Inf. Syst. Eng. 1-4 (2013)

8. Huotari, K., Hamari, J.: Defining gamification: a service marketing perspective. In: Proceeding of the 16th International Academic MindTrek Conference, pp. 17-22. ACM, New York, NY, USA (2012)

9. Dicheva, D., Dichev, C., Agre, G., Angelova, G.: Gamification in education: a systematic mapping study. Educ. Technol. Soc. 18 (2015)

10. Broer, J.: Gamification and the trough of disillusionment. In: Butz, A., Koch, M., Schlichter, J. (eds.) Mensch and Computer-Workshopband, pp. 389-395. De Gruyter Oldenbourg, Berlin (2014)

11. Arjoranta, J.: Game definitions: a Wittgensteinian approach. Game Stud. 14 (2014)

12. Hamari, J., Koivisto, J., Sarsa, H.: Does gamification work? - a literature review of empirical studies on gamification. In: Proceedings of the 47th Hawaii International Conference on System Sciences (2014) 